\title{
Emerging evidence for targeting mitochondrial metabolic dysfunction in cancer therapy
}

\author{
Yueming Zhu, ${ }^{1}$ Angela Elizabeth Dean, ${ }^{1}$ Nobuo Horikoshi, ${ }^{1}$ Collin Heer, ${ }^{2}$ Douglas R. Spitz, ${ }^{2}$ and David Gius ${ }^{1}$ \\ 'Department of Radiation Oncology, Robert H. Lurie Comprehensive Cancer Center, Feinberg School of Medicine, Northwestern University, Chicago, Illinois, USA. ${ }^{2}$ Free Radical and Radiation Biology Program, \\ Department of Radiation Oncology, Holden Comprehensive Cancer Center, University of lowa, lowa City, lowa, USA.
}

\begin{abstract}
Mammalian cells use a complex network of redox-dependent processes necessary to maintain cellular integrity during oxidative metabolism, as well as to protect against and/or adapt to stress. The disruption of these redox-dependent processes, including those in the mitochondria, creates a cellular environment permissive for progression to a malignant phenotype and the development of resistance to commonly used anticancer agents. An extension of this paradigm is that when these mitochondrial functions are altered by the events leading to transformation and ensuing downstream metabolic processes, they can be used as molecular biomarkers or targets in the development of new therapeutic interventions to selectively kill and/or sensitize cancer versus normal cells. In this Review we propose that mitochondrial oxidative metabolism is altered in tumor cells, and the central theme of this dysregulation is electron transport chain activity, folate metabolism, NADH/NADPH metabolism, thiol-mediated detoxification pathways, and redox-active metal ion metabolism. It is proposed that specific subgroups of human malignancies display distinct mitochondrial transformative and/or tumor signatures that may benefit from agents that target these pathways.
\end{abstract}

\section{Introduction}

Mitochondria contain the oxidation/reduction (redox) $\mathrm{O}_{2}$-consuming metabolic pathways necessary for cellular and organismal survival. The functions of these pathways include energy production and the removal and/or detoxification of damaging metabolites produced as by-products of oxidative phosphorylation (1-3). In this regard, mitochondria are constantly sensing energy availability, as well as the cell's current energy requirements, to ensure that the activities of the electron transport chain (ETC) and tricarboxylic acid (TCA) cycle match the cellular need for energy consumption (4-6). In addition, mitochondria also regulate the antioxidant enzymes and signal transduction pathways that lead to the detoxification of reactive by-products formed during energy production $(7,8)$. This regulatory balance is referred to as metabolic reprogramming, and it directs mitochondrial homeostasis.

The mitochondria in mammalian cells have evolved to monitor and maintain the integrity of mitochondrial function, as well as communicate and coordinate functions in other cellular organelles (911). In this regard, it is well established that disrupted normal mitochondrial function creates a cellular environment that is permissive for a host of human illnesses in both children and adults (12-14). In adults, a decline in mitochondrial quality and activity is more commonly observed with increasing age and appears to play a significant role in degenerative diseases associated with aging, including cardiovascular disease, neurodegenerative diseases, insulin resistance, carcinogenesis, and tumor cell resistance to therapy (15-19).

One of the most studied and debated mitochondrial metabolic abnormalities in human tumors is commonly referred to as

Conflict of interest: The authors have declared that no conflict of interest exists. Reference information: J Clin Invest. 2018;128(9):3682-3691.

https://doi.org/10.1172/JCI120844. the Warburg effect, but in the past few years this process has been shown to be more complex than simply an increase in glycolysis. In this regard, we now know that mitochondrial energy pathways entail changes in the regulation of both glycolysis and mitochondrial respiration, including oxidative phosphorylation, as compared with normal tissue, as well as higher flux through both of these pathways (20-22). However, attempts to target these processes in order to enhance anticancer therapy responses have not led to clinically applicable therapies $(23,24)$. In addition to changes in carbon flux, cancer cells tend to also exhibit significant increases in the production of superoxide $\left(\mathrm{O}_{2}^{-}\right)$and hydrogen peroxide $\left(\mathrm{H}_{2} \mathrm{O}_{2}\right)$, both of which can induce prooncogenic signaling pathways as well as directly damage cellular micromolecules $(22,25)$.

In this regard, tumor cells often demonstrate altered activity of mitochondrial enzymes that could compensate for changes in tumor cell ROS levels and downstream damage products by upregulating the activity of antioxidant defenses $(25,26)$. These observations, coupled with advances in metabolomic analysis and carbon tracing, provide tools to elucidate the underlying basis for mitochondrial metabolic abnormalities in cancer. These technologies have also advanced our understanding of the role of redox biology in cancer initiation, progression, and metastasis, as well as strengthening the hypothesis that aberrant mitochondrial oxidative pathways represent potential molecular targets for the development of specific therapeutic interventions (7, 22, 25, 27-29).

\section{Linking metabolism and gene expression in cancer cells}

In normally functioning cells, oxidative metabolism and gene expression are tightly coupled via the nonequilibrium steady-state fluxes of reactive metabolic by-products and electron carriers (i.e., $\mathrm{NADH}$ and $\mathrm{FADH}_{2}$ ). Thus, in healthy cells, the flow of electrons 
A Relationship between metabolism and gene expression

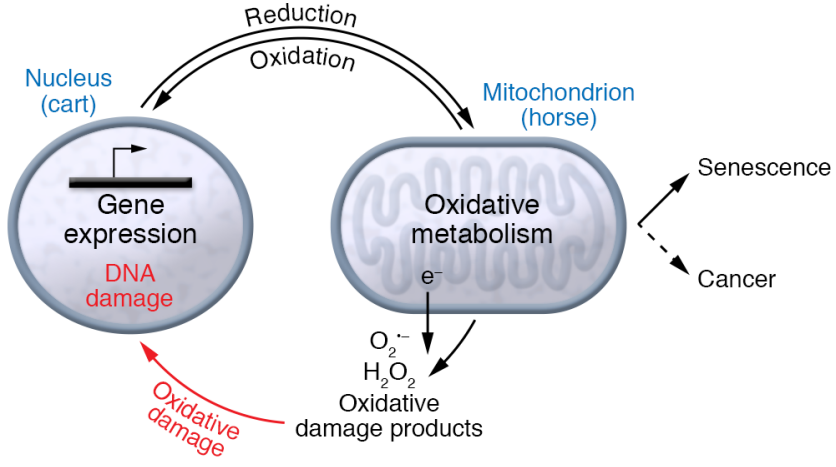

B Normal tissue damage

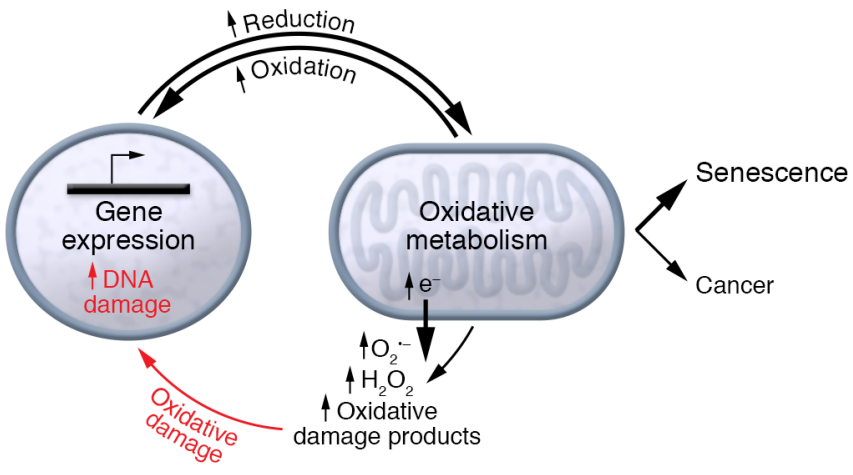

C Tumor metabolism

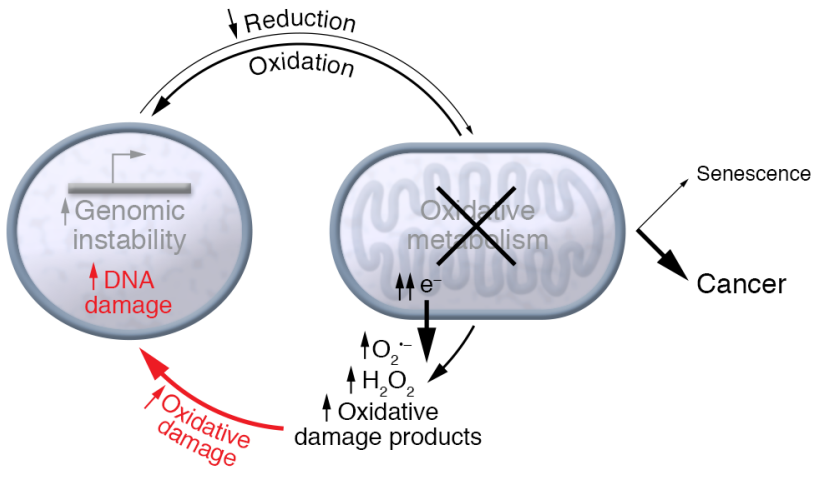

from energy-producing reactions should influence gene expression pathways that govern critical cellular processes to maintain a balance between normal cellular functions and differentiation. However, when this nonequilibrium steady state is disrupted, the reactive by-products of oxidative metabolism, such as $\mathrm{O}_{2}^{-{ }^{-}}$ $\mathrm{H}_{2} \mathrm{O}_{2}$, as well as reactive oxidative by-products (i.e., aldehydes and organic hydroperoxides), can cause covalent changes in the genome, leading to the gradual deterioration of metabolic gene expression pathways if unrepaired or misrepaired.

The horse (metabolism) and cart (gene expression) model provides a framework for understanding the fundamental relationship between cellular and mitochondrial metabolism, signal transduction, and gene expression in mammalian biology, as well as degenerative diseases associated with aging and cancer. In this regard, the essential mitochondrial and cytosolic redox metabolic
Figure 1. The horse and cart model describes the relationship between mitochondrial metabolism, signal transduction, and gene expression in mammalian biology, as well as in degenerative diseases associated with aging and cancer. (A) In healthy mammalian cells, the essential redox metabolic process occurring in the mitochondria and cytosol can be considered as the horse, and its related gene expression can be considered as the cart. In normal cells, oxidative metabolism and gene expression are tightly coupled via the nonequilibrium steady-state fluxes of reactive metabolic by-products and leaking electrons ( $\left.\mathrm{e}^{-}\right)$carriers, such as superoxide $\left(\mathrm{O}_{2}^{-{ }^{-}}\right)$ and hydrogen peroxide $\left(\mathrm{H}_{2} \mathrm{O}_{2}\right)$. The level of DNA damage that occurs in a healthy cell is partially mitigated by ongoing DNA repair processes. (B) When the nonequilibrium steady state is disrupted, ROS and reactive oxidative by-products produced by oxidative metabolism (the horse) can increase oxidative damage in the genome, which will lead to the gradual deterioration of gene expression (the cart). Accumulation of DNA damage leads to cellular senescence or cancer. (C) The deregulated oxidative metabolism in cancer cells produces genomic instability that will eventually drag the cart off the cliff, so to speak, to the valley of death.

processes necessary for maintaining living systems can be considered as the horse that is tethered to the nuclear gene expression pathways by redox-sensitive signaling (Figure 1A). Thus, it is proposed that there is a mechanistic relationship between glucose and $\mathrm{O}_{2}$ metabolism based on the ability to extract electrons from nutrient sources, via oxidation reactions, to generate ATP and reducing equivalents for biosynthesis while consuming $\mathrm{O}_{2}$ to dispose of the electrons onto water molecules. These essential interconnected cellular metabolic processes are coordinately linked by the flow of ATP, reducing equivalents, and reactive by-products of oxidative metabolism (i.e., $\mathrm{O}_{2}^{--}, \mathrm{H}_{2} \mathrm{O}_{2}$, organic hydroperoxides, etc.) through redox-sensitive signaling pathways to direct gene expression to control normal cellular functions that are closely matched to metabolic capabilities in the cell.

The horse and cart relationship can ultimately lead to a cellular environment that is permissive to gradual deterioration of multiple cellular processes, potentially due to stoichiometric mismatches between protein expression and metabolic machinery that impair efficient energy metabolism, as well as steadily increasing levels of reactive oxygen and nitrogen species. The resulting increasing inefficiency in oxidative metabolism and increasing steady-state levels of reactive species can lead to the exponential deterioration of the genome during aging, leading to senescence and death (Figure 1B). These age-related changes in reactive species and damage products are also accelerated by radiation and chemotherapy and can thus be targeted to inhibit normal tissue injury/regeneration during cancer therapy. In addition, Viale, Draetta, and colleagues showed that targeting mitochondrial respiration could induce the killing of oncogene ablation-resistant pancreatic cancer cells (Table 1), further suggesting the potential importance of targeting cancer cell metabolism in future therapeutic strategies (20).

In the case of carcinogenesis, we hypothesize that the emergence of a cellular and metabolic environment permissive for malignant transformation is due to the age-related loss of the horse and cart nonequilibrium steady state, leading to immortalization (possibly involving the induction of telomerase) as an adaptive response to the stress caused by oxidative damage to the genome. When the stoichiometry of ETC assembly is altered and creates mismatches, or the $\mathrm{O}_{2}$ supply is altered, or the activity of 


\section{Table 1. Mutated mitochondrial metabolic genes and altered metabolites}

\begin{tabular}{lcc}
$\begin{array}{l}\text { Mutated gene (or altered } \\
\text { metabolite) }\end{array}$ & $\begin{array}{c}\text { Mitochondrial function } \\
\text { affected }\end{array}$ & References \\
ND1 & ETC complex I & $130-140$ \\
ND2 & ETC complex I & $135,137-139,141$ \\
ND3 & ETC complex I & $137-139$ \\
ND4 & ETC complex I & $130,135-139$ \\
ND4L & ETC complex I & $131,135,137-139$ \\
ND5 & ETC complex I & $130,131,137-139,142$ \\
ND6 & ETC complex I & $135,137-139$ \\
CYTB & ETC complex III & $131,135,137-139,143$ \\
COX & ETC complex IV & $135,137-139,143$ \\
COXII & ETC complex IV & $137-139,142-144$ \\
COXIII & ETC complex IV & $131,135,137-139$ \\
ATPase 6 & ETC complex V & $139,141,142$ \\
ATPase 8 & ETC complex V & 139,143 \\
Actionase 2 & TCA cycle & $54,145-147$ \\
IDH & TCA cycle & $51-60$ \\
SDHA & TCA cycle & $54,62,64-66$ \\
FHA & TCA cycle & $54,148-150$ \\
CS & Oncometabolites & $54,78,151$ \\
2-HCA & Oncometabolites & $52,54,58,152$ \\
MnSOD & Redox metabolism & $153-155$ \\
AIn clinical trial. & & \\
\hline
\end{tabular}

ETC proteins is altered, then the residence time of electrons on sites that can mediate one-electron reductions of $\mathrm{O}_{2}$ increases, leading to increases in steady-state levels of $\mathrm{O}_{2}{ }^{--}$and $\mathrm{H}_{2} \mathrm{O}_{2}(21,22)$. Likewise, when ADP is high or mitochondrial membrane potential is dissipated (by proton ionophores or uncoupling proteins), electron flows to cytochrome oxidase increase in an attempt to reestablish membrane potential, leading to increased four-electron reductions of $\mathrm{O}_{2}$ to form $\mathrm{H}_{2} \mathrm{O}$. Finally, electron flows through ETC chains can be increased or reduced by shunting of carbon flux toward or away from the TCA cycle, respectively.

Given the complexity and multitude of proteins involved in regulating all of the aforementioned processes, it is logical to hypothesize that in fully transformed cancer cells, where mutation frequencies are estimated to be 200 times greater than in normal cells, oxidative metabolism becomes increasingly dysregulated relative to normal cells, contributing to continued progression to more aggressive malignant phenotypes. Once immortalization and malignant transformation occur, the living system has adapted to the dysfunctional relationship between oxidative metabolism, signal transduction, and gene expression; however, the transformed cells exhibit significant genomic instability, lose the ability to accomplish normal differentiation, lose control of cell proliferation, and continue to progress to malignancy. Moreover, the natural extension of this hypothesis is that continued targeting of only the malignant cell's dysfunctional gene expression, rather than also its aberrant metabolism (Figure 1C), significantly limits the potential ability to selectively kill cancer cells. Given this theoretical construct, we will discuss a model for targeting the hubs of disrupted normal oxidative metabolism in cancer cells that may lead to new combined-modality approaches to improve the outcome of patients diagnosed with cancer while preserving normal tissue function.

\section{NADPH in mitochondrial metabolism and tumor cell resistance}

It is established that cancer cells exhibit disrupted metabolic pathways and processes that can subsequently lead to unregulated cell growth and a tumor-permissive phenotype. For instance, even in the presence of sufficient oxygen, cancer cells depend on increases in glycolysis for their energy production, which is referred to as either "aerobic glycolysis" or the "Warburg effect" $(23,24)$. Switching of metabolism to glycolysis can be a normal event after heavy exercise leading to the accumulation of lactate from anaerobic glycolysis. However, increasing glycolytic metabolism under oxidative stress also stimulates the regeneration of NADPH from $\mathrm{NADP}^{+}$in the pentose cycle, formation of ribose sugars necessary for purine and pyrimidine synthesis/DNA repair, and formation of pyruvate, which can directly scavenge $\mathrm{H}_{2} \mathrm{O}_{2}$, as well as feed TCA cycle intermediates, such as isocitrate and malate, which are also capable of regenerating NADPH $(21,22,25-27)$.

$\mathrm{NADPH}$ serves as a source of reducing equivalents for the glutathione system, consisting of glutathione (GSH), glutathione disulfide (GSSG), glutathione peroxidases (GPx), and glutathione reductase (GR), and the thioredoxin system, consisting of thioredoxin $\left(\operatorname{Trx}_{[\mathrm{SH}] 2}\right)$, thioredoxin disulfide $\left(\operatorname{Trx}_{\mathrm{S}-\mathrm{S}}\right)$, peroxiredoxins (Prx), and thioredoxin reductase (TrxR). The glutathione and thioredoxin systems participate in the detoxification of $\mathrm{H}_{2} \mathrm{O}_{2}$ and organic hydroperoxides (ROOH) (Figure 2). $\mathrm{NADP}^{+}$can be reduced to NADPH by a variety of dehydrogenases, including glucose-6-phosphate dehydrogenase and 6-phosphogluconate dehydrogenase of the pentose phosphate pathway; malic enzyme and isocitrate dehydrogenase (IDH) of the TCA cycle; and glutamate dehydrogenase (28). In addition to direct reduction by $\mathrm{NADP}^{+}$-dependent dehydrogenases, the contribution of fatty acid oxidation in maintenance of NADPH and GSH levels is emerging in cancer biology $(29,30)$.

Recently, the contribution of the mitochondrial folate cycle enzymes mitochondrial methylene tetrahydrofolate dehydrogenase (MTHFD2) and aldehyde dehydrogenase-1-L2 (ALDH1L2) to NADPH production in cancer cells has become appreciated. MTHFD2, which is overexpressed in cancers (31), exhibits dual redox cofactor specificity and genetic inhibition of MTHFD2, or the cytosolic isoform (MTHFD1), decreasing NADPH/NADP ${ }^{+}$ and GSH/GSSG ratios $(32,33)$. Further, NADPH produced by ALDH1L2 confers resistance to oxidative stress required by melanoma metastases (34). These findings are confirmed by studies demonstrating the reliance of cancer cells on exogenous serine and glycine, two amino acids that drive the folate cycle to maintain $\mathrm{NADPH}$ and GSH $(34,35)$. In addition to $\mathrm{NADP}^{+}$-dependent dehydrogenases, $\mathrm{NAD}^{+}$kinase (NADK) has also been shown to exhibit control of NADPH levels in human cells, as phosphorylation of $\mathrm{NAD}^{+}$by NADK is the sole source of $\mathrm{NADP}^{+}(36)$.

$\mathrm{NAD}^{+}$metabolism may also explain age-related increases in cancer incidence. For example, an age-dependent increase in CD38 activity is reflected by a decline in $\mathrm{NAD}^{+}$, and this can be prevented by genetic or pharmacological CD38 inhibition $(37,38)$. 


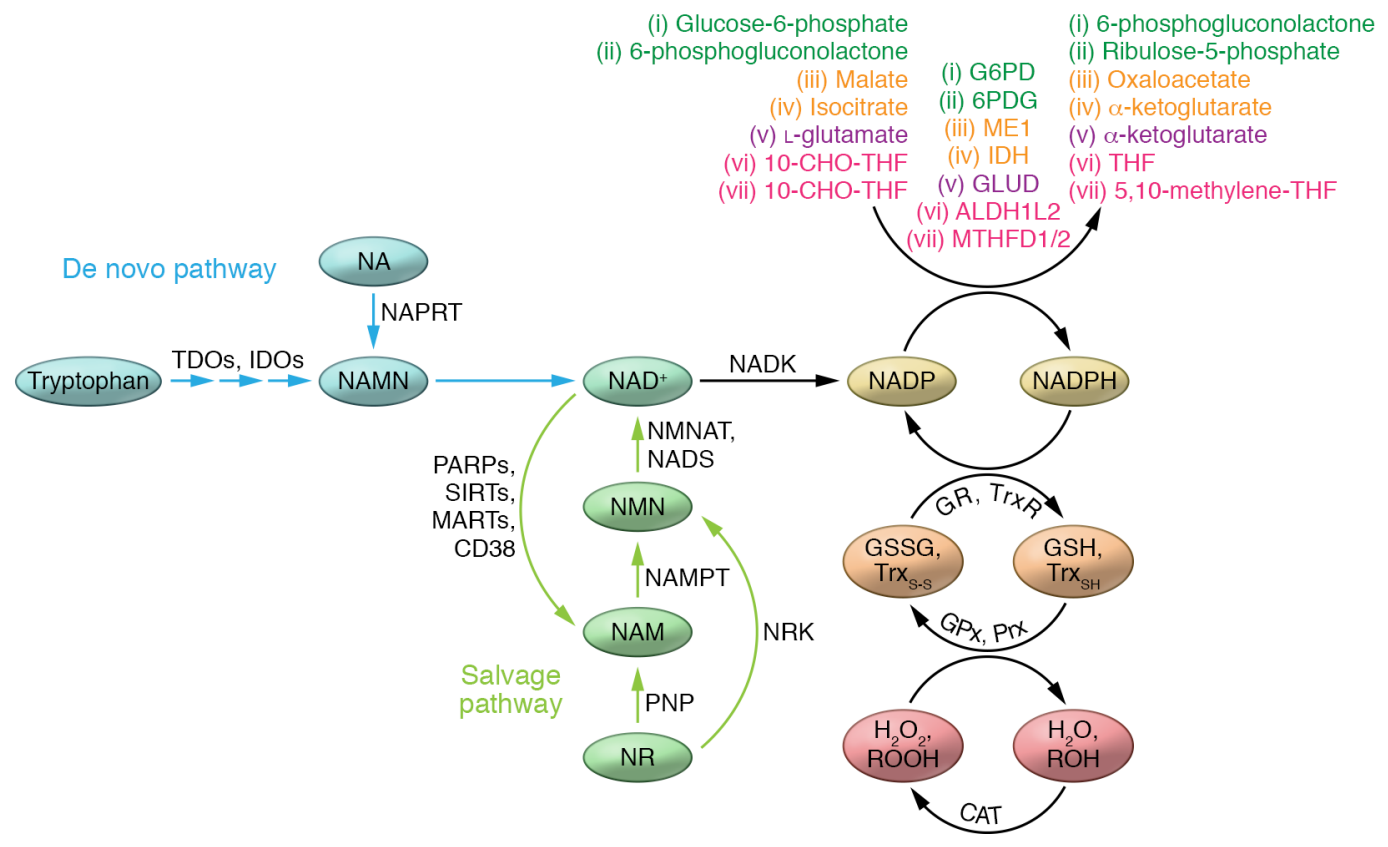

Figure 2. Interface of NAD synthesis and hydroperoxide metabolism. In the de novo synthesis pathway, L-tryptophan is converted to nicotinic acid mononucleotide (NAMN) in a series of eight steps. The initial, rate-limiting steps are catalyzed by tryptophan 2,3-dioxygenases (TDOs) and indolamine 2,3-dioxygenases (IDOs). The salvage pathway arm, controlled by the enzyme NAPRT, enters the pathway at this stage. NAMN is then enzymatically converted to $\mathrm{NAD}^{+}$by nicotinamide mononucleotide adenylyltransferase (NMNAT) and NADS (nicotinamide adenine dinucleotide sythetase). Nicotinamide (NAM) is an NAD+ precursor generated by deacetylation and ADP-ribosylation reactions catalyzed by sirtuins (SIRTs), poly(ADP-ribose) polymerases (PARPs), mono-ADP ribosyltransferases (MARTs), and ADP-ribosyl cyclases such as CD38. NAM can also be synthesized by NR kinases (NRKs), which catalyze the phosphorylation of nicotinamide riboside (NR). Nicotinamide phosphoribosyltransferase (NAMPT) catalyzes the regeneration of nicotinamide mononucleotide (NMN) from NAM. NMN is then enzymatically converted into NAD+ by NMNAT. NADP+ is synthesized from NAD+ by NAD kinase (NADK). $\mathrm{NADP}^{+}$can be reduced to NADPH by a variety of dehydrogenases. NADPH serves as a source of reducing equivalents for the glutathione system, consisting of GSH, GSSG, GPx, and GR, and the thioredoxin system, consisting of $\operatorname{Trx}_{5 \mathrm{~S}}, \operatorname{Trx}_{\mathrm{s}-5}, \operatorname{Prx}$, and TrxR. The glutathione and thioredoxin systems participate in the detoxification of $\mathrm{H}_{2} \mathrm{O}_{2}$ and organic hydroperoxides $(\mathrm{ROOH})$. Enzymatic reactions are color-coded to their metabolic pathway of origin: dark green, pentose phosphate pathway; orange, TCA cycle; fuchsia, one-carbon metabolism. G6PD, glucose-6-phosphate dehydrogenase; 6PDG, 6-phosphogluconate dehydrogenase; ME1, malic enzyme 1; 10-CHO-THF, 10-Formyltetrahydrofolate; GLUD, glutamate dehydrogenase; THF, tetrahydrofolate; CAT, catalase.

Age-dependent decreases in $\mathrm{NAD}^{+}$also correlate with reduced sirtuin activity, poly(ADP-ribose) polymerase (PARP) activity, and decreased mitophagy accompanied by mitochondrial dysfunction, increased ROS production, and genotoxicity (39-42). The emergence of many of these age-dependent phenomena can be slowed by $\mathrm{NAD}^{+}$precursor supplementation in the form of nicotinamide riboside, nicotinamide mononucleotide, or caloric restriction, suggesting that decreased $\mathrm{NAD}^{+}$plays a causal role in the aging processes (43-46). Thus, during aging, decreases in cellular $\mathrm{NAD}^{+}$result in the breakdown of PARP and sirtuin-mediated communication between the mitochondria (horse) and nucleus (cart) and subsequent loss of metabolic and genomic integrity (47, 48) that may explain the correlation between aging, mitochondrial dysfunction, and cancer incidence $(49,50)$.

Isocitrate is converted to $\alpha$-ketoglutarate by isocitrate dehydrogenase-2 (IDH2), a key rate-limiting TCA cycle enzyme that produces NADPH. Several studies have suggested that mutations in IDH2 play a role in carcinogenesis, specifically colon cancer, prostate carcinoma, acute lymphoblastic leukemia, and glioblastoma (Table 1). These mutations inactivate wild-type IDH enzymatic activity, leading to 2-hydroxyglutarate production (2-HG). Increased 2-HG can impact $\alpha$-ketoglutarate-dependent dioxygenase activity and alter various biological functions in tumors
(51-55). In this regard, the IDH2 inhibitor enasidenib is FDAapproved for acute myeloid leukemia, establishing TCA proteins as molecular targets (55-60).

\section{NAD in mitochondrial metabolism and tumor cell resistance}

Nicotinamide adenine dinucleotide is a coenzyme in redox reactions and thus exists as an oxidized form $\left(\mathrm{NAD}^{+}\right)$, as well as a reduced form (NADH). NAD metabolism has recently emerged as an intriguing molecular target to modify mitochondrial oxidative metabolism (61). For example, it was shown that circadian rhythms influence mitochondrial metabolism through cellular pathways that direct $\mathrm{NAD}^{+} / \mathrm{NADH}$ levels, as well as through the acetylation of key mitochondrial redox and detoxification proteins (61). Cells maintain significant concentrations of both $\mathrm{NAD}^{+}$and $\mathrm{NADH}$ with a high $\mathrm{NAD}^{+} / \mathrm{NADH}$ ratio ( $\sim 700$ in the cytoplasm, $3-10$ in the cell as a whole) that is favorable for oxidative reactions (2-4). In contrast, NADPH plays a major function as a reducing agent in anabolism, such as in fatty acid synthesis and photosynthesis, and thus the $\mathrm{NADP}^{+} / \mathrm{NADPH}$ ratio is kept very low (about 0.005$)(4,5)$. $\mathrm{NADP}^{+} / \mathrm{NADPH}$, which exists at roughly one-tenth of the concentration of $\mathrm{NAD}^{+} / \mathrm{NADH}$, is also a major chemical redox balance responder in cells. A Swiss-Prot database (accessed May 2018 at 
UniProt, www.uniprot.org) showed 20,349 entries for human proteins and 459 proteins that utilize NADs $\left(\mathrm{NAD}^{+}, \mathrm{NADH}, \mathrm{NADP}^{+}\right.$, and NADPH combined), which is $2.3 \%$ of all human proteins.

Succinate dehydrogenase $(\mathrm{SDH})$ is one of the proteins that utilize NADs and is involved in two essential cellular metabolic processes, the TCA cycle and the ETC. Mutations in the subunits of SDH (SDHA, SDHB, SDHC, and SDHD) in paraganglioma and gastrointestinal stromal tumor, renal carcinoma, and pheochromocytoma lead to loss of enzymatic function, increased ROS production $(54,62,63)$, and accumulation of succinate (Table 1$)$. ROS, as well as succinate, can independently or synergistically lead to the induction of a hypoxic response. In addition, accumulated succinate may inhibit $\alpha$-ketoglutarate-dependent dioxygenases and prolyl hydroxylase domain protein 3-mediated (PHD3mediated) apoptosis. In this regard, certain drugs, like SGI-110 (guadecitabine) and temozolomide, have been used in clinical trials for gastrointestinal stromal cancer, paraganglioma, and renal cell carcinoma (64-66).

\section{Mitochondrial compartmentalization of $\mathrm{NAD}^{+}$}

Although NADH is free to enter the intermembrane space through the outer mitochondrial membrane, it is not permeable into the inner mitochondrial membrane (30). Instead, the reducing equivalent of NADH is transported into the mitochondria via either the malate-aspartate shuttle or the glycerol-3-phosphate shuttle of the inner mitochondrial membrane (31). In addition, the different $\mathrm{NAD}^{+}$compartmental pools (i.e., nucleus, cytoplasm, mitochondria) can behave independently. As such, the maintenance of $\mathrm{NAD}^{+}$levels in each compartment is dependent on the activities of transportation and salvaging of the nicotinamide (NAM) produced by $\mathrm{NAD}^{+}$-consuming enzymes via nicotinamide phosphoribosyltransferase (NAMPT) and nicotinamide mononucleotide adenylyltransferase (NMNAT) activities (15). In fact, cancer cells appear to rely much more heavily on NAMPT than normal cells, and this pathway has been suggested as a potential target for radio-chemo-sensitization (67-70). Therefore, each $\mathrm{NAD}^{+}$pool is tailored to compartment-specific metabolic needs. For example, nuclear-localized $\mathrm{NAD}^{+}$was recently reported to regulate adipocyte differentiation (32).

Sirtuins (SIRTs) are a major target of $\mathrm{NAD}^{+}$signaling and direct, at least in some part, the acetylation status of mitochondrial proteins. In this regard, the total intracellular concentration of $\mathrm{NAD}^{+}$in mammals is estimated between approximately 200 and $500 \mu \mathrm{M}(6,33-35)$, and the binding affinity $\left(K_{\mathrm{m}}\right)$ of $\mathrm{NAD}^{+}$ to SIRT1, SIRT2, SIRT3, SIRT4, SIRT5, and SIRT6 is reported as 94-96 $\mu \mathrm{M}(36,37), 83 \mu \mathrm{M}(38), 880 \mu \mathrm{M}(39), 35 \mu \mathrm{M}(40), 980 \mu \mathrm{M}$ (41), and $26 \mu \mathrm{M}(42)$, respectively. Based on these data, it seems reasonable to propose that sirtuins can be classified into two categories: (a) SIRT2, SIRT4, and SIRT6, whose activity is unlikely to be rate-limited by $\mathrm{NAD}^{+}$, as $\mathrm{NAD}^{+}$availability is much higher than their $K_{\mathrm{m}}$; and (b) SIRT1, SIRT3, and SIRT5, whose $K_{\mathrm{m}}$ for $\mathrm{NAD}^{+}$falls within the physiological $\mathrm{NAD}^{+}$range. As such, it seems important to note that SIRT1 localizes in the nucleus, and $\mathrm{NAD}^{+}$ levels in the nucleus are below $100 \mu \mathrm{M}$, while $\mathrm{NAD}^{+}$concentrations in the mitochondria range up to the millimolar order. Thus, owing to their $K_{\mathrm{m}}$ values, $\mathrm{NAD}^{+}$could operate SIRT3 and SIRT5 as $\mathrm{NAD}^{+}$sensors. It is therefore proposed that the different concen- trations of $\mathrm{NAD}^{+}$in the various subcellular compartments may direct a specific cellular process downstream of the sirtuin proteins, and that mitochondrial sirtuins may be a potential molecular target for cancer therapeutics (71-74).

In this regard, it appears that slightly more than $65 \%$ of all mitochondrial proteins are constantly acetylated nonenzymatically because of the high concentration of acetyl-CoA and high $\mathrm{pH}$ ( $\mathrm{pH} \sim 8.0$ ) within the mitochondrial compartment (49-51). Therefore, it is proposed that the mitochondrial deacetylases play primary roles in regulating the mitochondrial acetylome network $(39,52-55)$. In addition, it seems reasonable to suggest that SIRT3, the primary mitochondrial deacetylase, also functions to deacetylate many mitochondrial proteins, e.g., in response to calorie restriction, fasting, and other conditions in which nutrient availability is limited $(49,50)$. SIRT3 plays critical roles in mitochondrial functions, such as repair, respiration, and dynamics. While SIRT3 directs the acetylation and enzymatic activity of a number of proteins involved in energy generation, it also regulates several key detoxification proteins that regulate cellular ROS. SIRT3 and its downstream proteins may be important molecular biomarkers and/or target proteins that alter mitochondrial ROS, leading to a cellular phenotype permissive for tumor cell cytotoxicity.

\section{Mitochondrial stress responses in carcinogenesis}

One of the best-described mechanisms for mitochondrial communication with other cellular compartments is through the release of ROS, and mitochondrial oxidants function in numerous signaling pathways (75-77). The mitochondrial respiratory chain is responsible for the production of $\operatorname{ROS}(19,25,78)$, and in normal cells, steady-state levels of ROS, via either production or detoxification, are tightly controlled and can act as secondary messengers to direct normal cellular functions (79). However, in stressed mitochondria, ROS can exist at nonphysiological levels that, in a specifically cellular context, may be harmful by damaging proteins, lipids, and DNA, thus contributing to mitochondrial dysfunction and carcinogenesis $(42,45-48)$.

SIRT3 has been demonstrated as a tumor suppressor that inhibits mitochondrial ROS production, at least in some significant part, through the activation of downstream deacetylation targets including SOD2, IDH2, and FoxO3a (52, 53, 59-62). Loss of SIRT3 also stabilizes hypoxia-inducible factor- $1 \alpha$ (HIF-1 $\alpha)$ as a result of increased ROS levels, directing metabolic pathways toward aerobic glycolysis to support tumor growth $(52,59)$. SIRT3 also regulates the malate-aspartate shuttle (63), which is critical to sustain a high rate of glycolysis in tumor cells, and mitochondrial glutamate oxaloacetate transaminase, both of these enzymes are SIRT3 targets and are the key components of the glycolysis shuttle. Further supporting its tumor suppressor role, expression of SIRT3 is downregulated in breast cancer, colon carcinoma, osteosarcoma, and hepatocellular carcinoma, and mice lacking Sirt3 spontaneously develop estrogen receptor-positive, highKi-67, poorly differentiated mammary tumors (53, 59, 64-66). Based on these results, it seems reasonable to propose that SIRT3 is positioned at the interface between $\mathrm{NAD}^{+} / \mathrm{NADH}$ biology and cellular ROS levels/detoxification enzymes, and as such, SIRT3 may be a potential target for the development of novel anticancer agents in these tumor types. 


\section{Targeting mitochondrial protein import/ transport in anticancer interventions}

The majority of mitochondrial precursor proteins encoded in the nucleus contain an N-terminal matrix-targeting sequence (MTS) to facilitate localization to the mitochondrial matrix. The MTScontaining proteins are first recognized by the translocase of the mitochondrial outer membrane complex (TOM complex) and then by the translocase of the inner membrane 23 complex (TIM23 complex) in the inner membrane (67). Upon translocation into the mitochondria, MTS is cleaved, and these proteins undergo chaperone-assisted folding and transport to specific locations (68). Protein trafficking requires ATP and the proton gradient generated by the respiratory chain, and thus would be disturbed by oxidative phosphorylation (OXPHOS) defects. Importantly, protein trafficking through the TIM23 complex is sensitive to multiple stressors and is inhibited by elevated ROS, mitonuclear protein imbalance, the status of the matrix-localized chaperone mtHSP70 (also known as HSPA9), and unfolded proteins as described below (69-71). In other words, TIM23-mediated protein trafficking is capable of pushing the cart and needs to be compensated by the horse.

The mitochondrial unfolded protein response (UPRmt) is a transcriptional program regulated by defined transcription factors, which are activated by mitochondrial perturbation/dysfunction through mitochondrial-nuclear communication. It is an adaptive stress response that functions to resolve the accumulation of unfolded proteins within mitochondria, which leads to oxidative stress, similar to its effect within other cellular compartments. Although the functions of many UPRmt-induced genes are still unknown, it is well established that the UPRmt is activated if mitochondrial function declines to promote repair and recovery.

Mitochondria contain multiple copies of a small circular genome (mtDNA) that encodes 13 OXPHOS proteins, as well as transfer RNAs and ribosomal RNAs required for their synthesis in the mitochondrial matrix space (72). The rest of the approximately 1,200 mitochondrial proteins are encoded by nuclear genome, translated in cytoplasm, and subsequently imported into mitochondria (73). Therefore, the disruption of stoichiometric balance between components of OXPHOS complexes I, III, IV, and V, including proteins encoded by both the mitochondrial and nuclear genomes, triggers UPRmt activation. In Caenorhabditis elegans, the activating transcription factor associated with stress (ATFS-1) is one of the transcription factors required for UPRmt, and contains an MTS in addition to a nuclear localization signal (NLS) (74). In cells with healthy mitochondria, the MTS prevails, and ATFS-1 is imported into mitochondria and degraded by the matrix-localized protease LON. When mitochondria are damaged, the NLS directs ATFS- 1 to the nucleus to activate transcription (74), and thus mitochondrial protein import is a key UPRmt regulatory mechanism. ATFS-1 also temporarily reduces OXPHOS gene transcription in both the nucleus and the mitochondria with increasing transcription of glycolysis components $(74,75)$, which likely allows cells to generate ATP in the cytosol to ensure survival and mitochondria recovery. Thus, the UPRmt and ROS appear to be closely connected in the mitochondria, and it seems reasonable to suggest that agents targeting this pathway, as well as the pathways discussed above, could be novel therapeutic interventions in the treatment of cancer patients.

\section{Aberrant mitochondrial oxidative metabolism in redox-sensitive cancer cells}

Glutathione (GSH) and the related enzymes, glutathione peroxidases (GPx1 and GPx4), glutaredoxin 2 (80), and glutathione reductase (GR), make up the major components of mitochondrial thiols that maintain redox reactions and mitochondrial metabolic homeostasis (81). In addition, thioredoxin-2 (Trx2), peroxiredoxin-3 (Prx3), and peroxiredoxin-5 (Prx5) also play functional roles in mitochondrial thiol metabolism $(82,83)$. GSH in mammalian cells participates in the detoxification processes by efficiently removing various hydroperoxides through its role as a cofactor for glutathione peroxidase, glutathione- $S$-transferases, and sulfiredoxins $(84,85)$. This mitochondrial thiol antioxidant system supports and provides electron sources for both the thioredoxin and glutaredoxin systems via NADPH, which is a major product of nicotinamide nucleotide transhydrogenase, glucose 6-phosphate dehydrogenase, and IDH2 (86). Folate metabolism is also strongly linked to thiol metabolism through the regulation of NADPH, formate, purine biosynthesis, and GSH metabolism (87-91), providing many new points of cancer cell-specific therapeutic intervention.

GSH also plays a role in cellular viability and redox balance by reducing peroxides, acting as a nucleophile as it shuffles target proteins between oxidized and reduced states, as well as the detoxifying lipid peroxidation-derived aldehydes (80, 91-95). Because mitochondrial GSSG cannot be exported, the dynamic ratio between GSH and GSSG could provide a controllable environment for disulfide bond formation during the folding of nascent proteins (95). Thus, it seems reasonable to propose that the dynamic ratio between GSH and GSSG, as well as the ratio between $\operatorname{Trx}_{[\mathrm{SH} / 2}$ and $\operatorname{Trx}_{s-s}$, which is disrupted in cancer cells, directs NADH/NADPH metabolism, folate metabolism, and ETCs.

The mitochondrial thiol antioxidants constitute an integrated regulatory system that exerts functions in a wide range of biological activities in mammalian cells, including maintenance of steadystate levels of hydrogen peroxide $\left(\mathrm{H}_{2} \mathrm{O}_{2}\right)$ and organic hydroperoxides (ROOH), which have an important role in maintaining mitochondrial and cellular redox homeostasis. Disruption of mitochondrial thiol antioxidant systems leads to accumulation of oxidative damage to lipids, proteins, and DNA, as well as proper assembly and function of ETCs. This oxidative damage contributes to radio-chemo-sensitization due to increased levels of $\mathrm{O}_{2}^{-{ }^{-}}$that liberate redox-active metals from ferritin $\left(\mathrm{Fe}^{2+}\right)$, and reduce $\mathrm{Fe}^{3+}$ to $\mathrm{Fe}^{2+}$, during redox cycling of pharmacological levels of ascorbate to selectively generate more ROS, as well as hydroxyl radical $(\cdot \mathrm{OH})$ through the Fenton reaction $(96,97)$. In addition, mitochondrial ETC-generated superoxide $\left(\mathrm{O}_{2}^{-}\right)$is converted by manganese superoxide dismutase (MnSOD) to $\mathrm{H}_{2} \mathrm{O}_{2}$, and this reaction is thought to be tumor suppressive (98). Reactive nitrogen species (RNS) can also be generated in the form of nitric oxide (·NO), which can react with $\mathrm{O}_{2}^{-}(99,100)$ to form peroxynitrite, which plays an important role in thiol-sensing pathways as well as anticancer therapy cytotoxicity. In contrast, the subsequent accumulation of aberrant levels of ROS or RNS can lead to oxidative and nitrosative damage, leading to genomic instability, protein and lipid oxidation, and altered mitochondrial metabolism, all of which lead to altered cell survival, growth, and proliferation $(101,102)$.

Among the different ROS generated in mitochondrial oxidative and respiratory metabolism, $\mathrm{H}_{2} \mathrm{O}_{2}$ is considered as one of the most 
critical redox signaling molecules and one of the ROS most relevant to cancer therapy (96). The levels of mitochondrial $\mathrm{H}_{2} \mathrm{O}_{2}$ are determined by a wide range of processes, including MnSOD, which is the key modulator for controlling $\mathrm{O}_{2}^{--}$redox balance $(98,103,104)$. The mitochondrial thiol system is crucial to maintain the redox balance between production and elimination of $\mathrm{H}_{2} \mathrm{O}_{2}$ and other organic hydroperoxides. In addition, many studies have shown that the disruption of the correct physiological balance of mitochondrial $\mathrm{H}_{2} \mathrm{O}_{2} /$ ROS homeostasis is a driving factor, at least in some part, in many diseases, such as carcinogenesis/tumorigenesis $(19,74,105,106)$.

It is an established paradigm in cancer research that thiol pathways, whose function is altered in tumor cells, are also potential molecular targets for new therapeutic interventions (98, 107-109). Moreover, compared with normal healthy cells, tumor cells exhibit an increased steady-state level of ROS, including $\mathrm{H}_{2} \mathrm{O}_{2}$, due to the altered mitochondrial metabolic processes and uncontrolled proliferation $(22,96,104,110)$. Although it was previously thought that ROS are always cytotoxic in both normal cells and cancer cells, it is not that simple. There is an essential role for $\mathrm{O}_{2}^{-{ }^{-}}$in normal signaling processes. Moreover, a certain amount of $\mathrm{ROS}\left(\mathrm{H}_{2} \mathrm{O}_{2}\right.$ in particular) stimulates cancer cell proliferation through modifications in the signaling pathways $(111,112)$. This idea fits comfortably into the cart and horse model, whereby the $\mathrm{H}_{2} \mathrm{O}_{2}$ produced by the "horse" signals alterations in gene expression through the redoxsensitive thiol signaling networks (Figure 1).

In regard to $\mathrm{H}_{2} \mathrm{O}_{2}$ signaling, studies have demonstrated that $\mathrm{H}_{2} \mathrm{O}_{2}$ in tumor cells stimulates the phosphorylation of PI3K/AKT, activates the HIF-1 $\alpha$ pathway $(77,113,114)$, and alters the tumor microenvironment that promotes angiogenesis through EGF activation, all of which promote a tumor-permissive phenotype (112, 113). Because of the close link between ROS, thiol redox signaling, and cellular processes, thiol antioxidant machinery plays an important role in regulating the redox balance and participates in cell proliferation and survival, cellular metabolism, and genomic integrity. $\mathrm{H}_{2} \mathrm{O}_{2}$ has also been shown to reversibly oxidize critical cysteine thiol groups of phosphatases, and $\mathrm{H}_{2} \mathrm{O}_{2}$ can hyperactivate PI3K/AKT/ mTOR by oxidizing and inactivating the phosphatases PTEN and PTP1B, which are negative regulators of PI3K/AKT signaling (115, 116). Moreover, $\mathrm{H}_{2} \mathrm{O}_{2}$ could also oxidize prolyl hydroxylase domain protein 2 (PHD2), which can lead to the oncogenic stabilization of HIF- $1 \alpha$ protein and promote oncogenic transformation.

In this regard, targeting of deregulated redox pathways in cancer cells is becoming increasingly important in experimental therapeutics. Specifically, agents such as metformin or phenformin appear to inhibit the proliferation and growth of certain types of cancer $(117,118)$. Several studies have shown that metformin could inhibit ETC complex I or the mTOR pathway by activating AMPK, and further decrease activation of IGF-1/insulin receptor, AKT, and ERK signaling, which could eventually lead to growth inhibition and/or apoptotic death. Because of the promising effects of metformin on AMPK-mediated redox-sensitive pathways, there are many trials assessing the usefulness of metformin in cancer treatment and cancer prevention (118-121).

In addition, in tumor biology, many studies have also suggested that mitochondrial thiols are involved in tumorigenesis, tumor progression, metastasis of cancer cells, and tumor therapy resistance (122-124). Recent studies also suggested that $\mathrm{H}_{2} \mathrm{O}_{2}$ could rely on thiol antioxidant systems to sense and transduce the redox signals (125). In mammalian cells, thiol antioxidant enzymes like Prx or GPx can receive $\mathrm{H}_{2} \mathrm{O}_{2}$ oxidation and transfer the oxidation to the target protein. For example, mitochondrial Prx has been shown to be reversibly hyperoxidized and inactivated by $\mathrm{H}_{2} \mathrm{O}_{2}$ to allow for localized $\mathrm{H}_{2} \mathrm{O}_{2}$ accumulation for target protein oxidation $(126,127)$. In addition, it has been suggested that GSH or reduced Trx recycles the oxidized scavenger back to its reduced state and transmits the signal to the target protein, and $\mathrm{H}_{2} \mathrm{O}_{2}$ oxidation of the scavenging enzyme may result in target protein dissociation and activation $(94,122)$. These critical thiol-based redox-sensitive signaling pathways, coupled with the increased steady-state levels of mitochondrial ROS in cancer cells, provide a clear biochemical rationale for a combined modality of cancer cell targets for selectively sensitizing cancers to cytotoxic therapeutic agents, while sparing normal tissues from the devastating effects of chemotherapy and radiation.

\section{Conclusions}

The disruption of normal mitochondrial physiology is a hallmark of cancer $(128,129)$, and with each passing year, our understanding of the link between aberrant metabolism and carcinogenesis grows. In this regard, the horse and cart model exhibits the relationship among the mechanisms by which tumor cells establish aberrant regulation of cellular and mitochondrial metabolism, signal transduction, and gene expression in cancer biology. Specifically, it has been proposed that oxidative metabolism (the horse) and gene expression (the cart) are normally tightly coupled through nonequilibrium steady-state fluxes of reactive metabolic by-products, electron flow from reactions governing energy production, and the cellular pathways governing growth and development. In addition, coordinated energy production, and the generation of reducing equivalents required for normal cellular physiology, deteriorate as an exponential function of aging and during progression to malignancy. Thus, this model predicts that metabolic oxidation reactions, when disrupted, lead to the formation of ROS and oxidative products detrimental to normal cellular processes and a damagepermissive phenotype of diseases associated with aging and cancer that can be targeted to improve human health.

\section{Acknowledgments}

DG is supported by NIH grants 2R01-CA152601-A1, 1R01CA152799-01A1, 1R01-CA168292-01A1, and 1R01-CA21402501, the Avon Foundation for Breast Cancer Research, the Lynn Sage Cancer Research Foundation, the Zell Family Foundation, and the Chicago Biomedical Consortium, as well as support from the Searle Funds at The Chicago Community. YZ is supported by a Robert H. Lurie Comprehensive Cancer Center Translation Bridge Fellowship Award. Melissa Stauffer of Scientific Editing Solutions provided editorial assistance. DRS is supported by NIH grants R01-CA182804 and P30-CA086862. We also thank Gareth Smith for helping with figure presentations.

Address correspondence to: David Gius, Department of Radiation Oncology, Northwestern University, Feinberg School of Medicine, Room 3-119, Lurie Research Building, 303 East Superior, Chicago, Illinois 60611, USA. Phone: 312.503.2053; Email: david.gius@ northwestern.edu. 
1. Wei YH, Ma YS, Lee HC, Lee CF, Lu CY. Mitochondrial theory of aging matures - roles of mtDNA mutation and oxidative stress in human aging. Zhonghua Yi Xue Za Zhi (Taipei). 2001;64(5):259-270.

2. Singh KK. Mitochondrial dysfunction is a common phenotype in aging and cancer. Ann N Y Acad Sci. 2004;1019:260-264.

3. Berneburg M, Kamenisch Y, Krutmann J, Rocken M. 'To repair or not to repair - no longer a question': repair of mitochondrial DNA shielding against age and cancer. Exp Dermatol. 2006;15(12):1005-1015.

4. Houstek J, Pícková A, Vojtísková A, Mrácek T, Pecina P, Jesina P. Mitochondrial diseases and genetic defects of ATP synthase. Biochim Biophys Acta. 2006;1757(9-10):1400-1405.

5. Samudio I, Fiegl M, Andreeff M. Mitochondrial uncoupling and the Warburg effect: molecular basis for the reprogramming of cancer cell metabolism. Cancer Res. 2009;69(6):2163-2166.

6. Li X, Kazgan N. Mammalian sirtuins and energy metabolism. Int J Biol Sci. 2011;7(5):575-587.

7. Zou X, Santa-Maria CA, O'Brien J, Gius D, Zhu Y. Manganese superoxide dismutase acetylation and dysregulation, due to loss of SIRT 3 activity, promote a luminal B-like breast carcinogenicpermissive phenotype. Antioxid Redox Signal. 2016;25(6):326-336.

8. Diebold L, Chandel NS. Mitochondrial ROS regulation of proliferating cells. Free Radic Biol Med. 2016;100:86-93.

9. Mallakin A, et al. Mutually exclusive inactivation of DMP1 and ARF/p53 in lung cancer. Cancer Cell. 2007;12(4):381-394.

10. Uren AG, et al. Large-scale mutagenesis in p19(ARF)- and p53-deficient mice identifies cancer genes and their collaborative networks. Cell. 2008;133(4):727-741.

11. Vousden KH, Prives C. Blinded by the light: the growing complexity of p53. Cell. 2009;137(3):413-431.

12. Koo B, et al. Mitochondrial encephalomyopathy, lactic acidosis, stroke-like episodes (MELAS): clinical, radiological, pathological, and genetic observations. Ann Neurol. 1993;34(1):25-32.

13. Christodoulou J, Petrova-Benedict R, Robinson BH, Jay V, Clarke JT. An unusual patient with the neonatal Marfan phenotype and mitochondrial complex I deficiency. Eur J Pediatr. 1993;152(5):428-432.

14. van Ekeren GJ, Cornelissen EA, Stadhouders $\mathrm{AM}$, Sengers RC. Increased volume density of peripheral mitochondria in skeletal muscle of children with exercise intolerance. Eur J Pediatr. 1991;150(10):744-750.

15. Greger V, Passarge E, Höpping W, Messmer E, Horsthemke B. Epigenetic changes may contribute to the formation and spontaneous regression of retinoblastoma. Hum Genet. 1989;83(2):155-158.

16. Baker SJ, Markowitz S, Fearon ER, Willson JK, Vogelstein B. Suppression of human colorectal carcinoma cell growth by wild-type p53. Science. 1990;249(4971):912-915.

17. Feinberg AP, et al. Multiple tumor suppressor genes in multistep carcinogenesis. Tohoku JExp Med.1992;168(2):149-152.

18. Sherr CJ, McCormick F. The RB and $\mathrm{p} 53$ pathways in cancer. Cancer Cell. 2002;2(2):103-112.
19. Spitz DR, Azzam EI, Li JJ, Gius D. Metabolic oxidation/reduction reactions and cellular responses to ionizing radiation: a unifying concept in stress response biology. Cancer Metastasis Rev. 2004;23(3-4):311-322.

20. Viale A, et al. Oncogene ablation-resistant pancreatic cancer cells depend on mitochondrial function. Nature. 2014;514(7524):628-632.

21. Spitz DR, Sim JE, Ridnour LA, Galoforo SS, Lee YJ. Glucose deprivation-induced oxidative stress in human tumor cells. A fundamental defect in metabolism? Ann N Y Acad Sci. 2000;899:349-362.

22. Aykin-Burns N, Ahmad IM, Zhu Y, Oberley LW, Spitz DR. Increased levels of superoxide and $\mathrm{H}_{2} \mathrm{O}_{2}$ mediate the differential susceptibility of cancer cells versus normal cells to glucose deprivation. Biochem J. 2009;418(1):29-37.

23. Warburg O, Wind F, Negelein E. The metabolism of tumors in the body. J Gen Physiol. 1927;8(6):519-530.

24. Warburg $\mathrm{O}$. The chemical constitution of respiration ferment. Science. 1928;68(1767):437-443.

25. Tuttle SW, Varnes ME, Mitchell JB, Biaglow JE. Sensitivity to chemical oxidants and radiation in $\mathrm{CHO}$ cell lines deficient in oxidative pentose cycle activity. Int J Radiat Oncol Biol Phys. 1992;22(4):671-675.

26. Ahmad IM, et al. Mitochondrial $\mathrm{O}_{2}^{-}$and $\mathrm{H}_{2} \mathrm{O}_{2}$ mediate glucose deprivation-induced stress in human cancer cells. J Biol Chem. 2005;280(6):4254-4263.

27. Simons AL, et al. Enhanced response of human head and neck cancer xenograft tumors to cisplatin combined with 2-deoxy-D-glucose correlates with increased 18F-FDG uptake as determined by PET imaging. Int J Radiat Oncol Biol Phys. 2007;69(4):1222-1230.

28. Jin L, et al. Glutamate dehydrogenase 1 signals through antioxidant glutathione peroxidase 1 to regulate redox homeostasis and tumor growth. Cancer Cell. 2015;27(2):257-270.

29. Pike LS, Smift AL, Croteau NJ, Ferrick DA, Wu M. Inhibition of fatty acid oxidation by etomoxir impairs NADPH production and increases reactive oxygen species resulting in ATP depletion and cell death in human glioblastoma cells. Biochim Biophys Acta. 2011;1807(6):726-734.

30. Jeon SM, Chandel NS, Hay N. AMPK regulates NADPH homeostasis to promote tumour cell survival during energy stress. Nature. 2012;485(7400):661-665.

31. Shin M, Momb J, Appling DR. Human mitochondrial MTHFD2 is a dual redox cofactor-specific methylenetetrahydrofolate dehydrogenase/ methenyltetrahydrofolate cyclohydrolase. Cancer Metab. 2017;5:11.

32. Lewis CA, et al. Tracing compartmentalized NADPH metabolism in the cytosol and mitochondria of mammalian cells. Mol Cell. 2014;55(2):253-263.

33. Ducker Gregory S, et al. Reversal of cytosolic one-carbon flux compensates for loss of the mitochondrial folate pathway. Cell Metab. 2016;24(4):640-641.

34. Piskounova E, et al. Oxidative stress inhibits distant metastasis by human melanoma cells. Nature. 2015;527(7577):186-191.
35. Jain M, et al. Metabolite profiling identifies a key role for glycine in rapid cancer cell proliferation. Science. 2012;336(6084):1040-1044.

36. Pollak N, Niere M, Ziegler M. NAD kinase levels control the NADPH concentration in human cells. J Biol Chem. 2007;282(46):33562-33571.

37. Camacho-Pereira J, et al. CD38 dictates agerelated NAD decline and mitochondrial dysfunction through an SIRT3-dependent mechanism. Cell Metab. 2016;23(6):1127-1139.

38. Aksoy P, White TA, Thompson M, Chini EN. Regulation of intracellular levels of NAD: a novel role for CD38. Biochem Biophys Res Commun. 2006;345(4):1386-1392.

39. Cantó C, et al. The $\mathrm{NAD}(+)$ precursor nicotinamide riboside enhances oxidative metabolism and protects against high-fat diet-induced obesity. Cell Metab. 2012;15(6):838-847.

40. Belenky P, Racette FG, Bogan KL, McClure JM, Smith JS, Brenner C. Nicotinamide riboside promotes Sir2 silencing and extends lifespan via Nrk and Urh1/Pnp1/Meu1 pathways to NAD ${ }^{+}$. Cell. 2007;129(3):473-484.

41. Mills KF, et al. Long-term administration of nicotinamide mononucleotide mitigates ageassociated physiological decline in mice. Cell Metab. 2016;24(6):795-806.

42. Zhang $\mathrm{H}$, et al. $\mathrm{NAD}^{+}$repletion improves mitochondrial and stem cell function and enhances life span in mice. Science. 2016;352(6292):1436-1443.

43. Frederick DW, et al. Loss of NAD homeostasis leads to progressive and reversible degeneration of skeletal muscle. Cell Metab. 2016;24(2):269-282.

44. Liu G, et al. Loss of NAD-dependent protein deacetylase sirtuin-2 alters mitochondrial protein acetylation and dysregulates mitophagy. Antioxid Redox Signal. 2017;26(15):849-863.

45. Fang EF, et al. Defective mitophagy in XPA via PARP-1 hyperactivation and NAD $(+) /$ SIRT1 reduction. Cell. 2014;157(4):882-896.

46. Weindruch R. Effect of caloric restriction on age-associated cancers. Exp Gerontol. 1992;27(5-6):575-581.

47. Mapuskar KA, et al. Mitochondrial superoxide increases age-associated susceptibility of human dermal fibroblasts to radiation and chemotherapy. Cancer Res. 2017;77(18):5054-5067.

48. Imai SI, Guarente L. It takes two to tango: $\mathrm{NAD}^{+}$ and sirtuins in aging/longevity control. NPJ Aging Mech Dis. 2016;2:16017.

49. Saunders LR, Verdin E. Sirtuins: critical regulators at the crossroads between cancer and aging. Oncogene. 2007;26(37):5489-5504.

50. Guarente L. Sirtuins, aging, and medicine. N Engl JMed. 2011;364(23):2235-2244.

51. Dang L, et al. Cancer-associated IDH1 mutations produce 2-hydroxyglutarate. Nature. 2010;465(7300):966.

52. Parker SJ, Metallo CM. Metabolic consequences of oncogenic IDH mutations. Pharmacol Ther. 2015;152:54-62.

53. Parsons DW, et al. An integrated genomic analysis of human glioblastoma multiforme. Science. 2008;321(5897):1807-1812.

54. Sajnani K, Islam F, Smith RA, Gopalan V, Lam AK. Genetic alterations in Krebs cycle and its impact on cancer pathogenesis. Biochimie. 2017;135:164-172. 
55. Mardis ER, et al. Recurring mutations found by sequencing an acute myeloid leukemia genome. N Engl JMed. 2009;361(11):1058-1066.

56. Cohen AL, Holmen SL, Colman H. IDH1 and IDH2 mutations in gliomas. Curr Neurol Neurosci Rep. 2013;13(5):345.

57. Yan $\mathrm{H}$, et al. IDH1 and IDH2 mutations in gliomas. N Engl J Med. 2009;360(8):765-773.

58 . Borger DR, et al. Frequent mutation of isocitrate dehydrogenase (IDH) 1 and IDH2 in cholangiocarcinoma identified through broad-based tumor genotyping. Oncologist. 2012;17(1):72-79.

59. Sjoblom T, et al. The consensus coding sequences of human breast and colorectal cancers. Science. 2006;314(5797):268-274.

60. Kang MR, et al. Mutational analysis of IDH1 codon 132 in glioblastomas and other common cancers. Int J Cancer. 2009;125(2):353-355.

61. Peek CB, et al. Circadian clock $\mathrm{NAD}^{+}$cycle drives mitochondrial oxidative metabolism in mice. Science. 2013;342(6158):1243417.

62. Bardella C, Pollard PJ, Tomlinson I. SDH mutations in cancer. Biochim Biophys Acta. 2011;1807(11):1432-1443.

63. Ricketts CJ, et al. Succinate dehydrogenase kidney cancer: an aggressive example of the Warburg effect in cancer. JUrol. 2012;188(6):2063-2071.

64. Ricketts C, et al. Germline SDHB mutations and familial renal cell carcinoma. J Natl Cancer Inst. 2008;100(17):1260-1262.

65. Janeway KA, et al. Defects in succinate dehydrogenase in gastrointestinal stromal tumors lacking KIT and PDGFRA mutations. Proc Natl Acad Sci U S A. 2011;108(1):314-318.

66. Letouzé E, et al. SDH mutations establish a hypermethylator phenotype in paraganglioma. Cancer Cell. 2013;23(6):739-752.

67. Lee J, et al. Selective cytotoxicity of the NAMPT inhibitor FK866 toward gastric cancer cells with markers of the epithelial-mesenchymal transition, due to loss of NAPRT [published online ahead of print May 15, 2018]. Gastroenterology. https://doi.org/10.1053/j.gastro.2018.05.024.

68. Ohanna M, et al. Pivotal role of NAMPT in the switch of melanoma cells toward an invasive and drug-resistant phenotype. Genes Dev. 2018;32(5-6):448-461.

69. Piacente F, et al. Nicotinic acid phosphoribosyltransferase regulates cancer cell metabolism, susceptibility to NAMPT inhibitors, and DNA repair. Cancer Res. 2017;77(14):3857-3869.

70. Elf AK, et al. NAMPT inhibitor GMX1778 enhances the efficacy of 177Lu-DOTATATE treatment of neuroendocrine tumors. J Nucl Med. 2017;58(2):288-292.

71. Pillai VB, et al. Honokiol blocks and reverses cardiac hypertrophy in mice by activating mitochondrial Sirt3. Nat Commun. 2015;6:6656.

72. Tao R, Vassilopoulos A, Parisiadou L, Yan Y, Gius D. Regulation of MnSOD enzymatic activity by Sirt 3 connects the mitochondrial acetylome signaling networks to aging and carcinogenesis. Antioxid Redox Signal. 2014;20(10):1646-1654.

73. Zhu Y, Yan Y, Principe DR, Zou X, Vassilopoulos A, Gius D. SIRT3 and SIRT4 are mitochondrial tumor suppressor proteins that connect mitochondrial metabolism and carcinogenesis. Cancer Metab. 2014;2:15.
74. Park SH, et al. Sirt3, mitochondrial ROS, ageing, and carcinogenesis. Int J Mol Sci. 2011;12(9):6226-6239.

75. Mapuskar KA, et al. Mitochondrial superoxide increases age-associated susceptibility of human dermal fibroblasts to radiation and chemotherapy. Cancer Res. 2017;77(18):5054-5067.

76. Du C, et al. Mitochondrial ROS and radiation induced transformation in mouse embryonic fibroblasts. Cancer Biol Ther. 2009;8(20):1962-1971.

77. Wang M, et al. Manganese superoxide dismutase suppresses hypoxic induction of hypoxia-inducible factor- $1 \alpha$ and vascular endothelial growth factor. Oncogene. 2005;24(55):8154-8166.

78. Chen L, et al. Citrate synthase expression affects tumor phenotype and drug resistance in human ovarian carcinoma. PLoS One. 2014;9(12):e115708.

79. Sarsour EH, Venkataraman S, Kalen AL, Oberley LW, Goswami PC. Manganese superoxide dismutase activity regulates transitions between quiescent and proliferative growth. Aging Cell. 2008;7(3):405-417.

80. Allen EM, Mieyal JJ. Protein-thiol oxidation and cell death: regulatory role of glutaredoxins. Antioxid Redox Signal. 2012;17(12):1748-1763.

81. Mitchell JB, Russo A. The role of glutathione in radiation and drug induced cytotoxicity. $\mathrm{Br} \mathrm{J}$ Cancer Suppl. 1987;8:96-104.

82. Du Y, Zhang H, Lu J, Holmgren A. Glutathione and glutaredoxin act as a backup of human thioredoxin reductase 1 to reduce thioredoxin 1 preventing cell death by aurothioglucose. J Biol Chem. 2012;287(45):38210-38219.

83. Hanschmann EM, et al. Both thioredoxin 2 and glutaredoxin 2 contribute to the reduction of the mitochondrial 2-Cys peroxiredoxin Prx3. J Biol Chem. 2010;285(52):40699-40705.

84. Ansenberger-Fricano K, et al. The peroxidase activity of mitochondrial superoxide dismutase. Free Radic Biol Med. 2013;54:116-124.

85. Berggren MI, Husbeck B, Samulitis B, Baker AF, Gallegos A, Powis G. Thioredoxin peroxidase-1 (peroxiredoxin-1) is increased in thioredoxin-1 transfected cells and results in enhanced protection against apoptosis caused by hydrogen peroxide but not by other agents including dexamethasone, etoposide, and doxorubicin. Arch Biochem Biophys. 2001;392(1):103-109.

86. Beer SM, et al. Glutaredoxin 2 catalyzes the reversible oxidation and glutathionylation of mitochondrial membrane thiol proteins: implications for mitochondrial redox regulation and antioxidant DEFENSE. J Biol Chem. 2004;279(46):47939-47951.

87. Lee D, Wong CC. The folate cycle is a new metabolic weakness of cancer. Mol Cell Oncol. 2017;4(6):e1327004.

88. Fan J, Ye J, Kamphorst JJ, Shlomi T, Thompson CB, Rabinowitz JD. Quantitative flux analysis reveals folate-dependent NADPH production. Nature. 2014;510(7504):298-302.

89. Konno M, et al. The one-carbon metabolism pathway highlights therapeutic targets for gastrointestinal cancer. Int J Oncol. 2017;50(4):1057-1063.

90. Semenza GL. Hypoxia-inducible factors: coupling glucose metabolism and redox regulation with induction of the breast cancer stem cell phe- notype. EMBO J. 2017;36(3):252-259.

91. Yang M, Vousden KH. Serine and one-carbon metabolism in cancer. Nat Rev Cancer. 2016;16(10):650-662.

92. Spitz DR, Sullivan SJ, Malcolm RR, Roberts RJ. Glutathione dependent metabolism and detoxification of 4-hydroxy-2-nonenal. Free Radic Biol Med.1991;11(4):415-423.

93. Heit C, Dong H, Chen Y, Shah YM, Thompson DC, Vasiliou V. Transgenic mouse models for alcohol metabolism, toxicity, and cancer. Adv Exp Med Biol. 2015;815:375-387.

94. Marí M, Morales A, Colell A, García-Ruiz C, Fernández-Checa JC. Mitochondrial glutathione, a key survival antioxidant. Antioxid Redox Signal. 2009;11(11):2685-2700.

95. Hwang C, Sinskey AJ, Lodish HF. Oxidized redox state of glutathione in the endoplasmic reticulum. Science. 1992;257(5076):1496-1502.

96. Schoenfeld JD, et al. O2(-) and H2O2-mediated disruption of Fe metabolism causes the differential susceptibility of NSCLC and GBM cancer cells to pharmacological ascorbate. Cancer Cell. 2017;32(2):268

97. Du J, et al. Pharmacological ascorbate radiosensitizes pancreatic cancer. Cancer Res. 2015;75(16):3314-3326

98. Oberley LW. Mechanism of the tumor suppres sive effect of MnSOD overexpression. Biomed Pharmacother. 2005;59(4):143-148.

99. Murphy MP. How mitochondria produce reactive oxygen species. Biochem J. 2009;417(1):1-13.

100.Boveris A. Mitochondrial production of superoxide radical and hydrogen peroxide. Adv Exp Med Biol. 1977;78:67-82.

101.Holmström KM, Finkel T. Cellular mechanisms and physiological consequences of redoxdependent signalling. Nat Rev Mol Cell Biol. 2014;15(6):411-421.

102. Schieber M, Chandel NS. ROS function in redox signaling and oxidative stress. Curr Biol. 2014;24(10):R453-R462.

103. Oberley LW, Buettner GR. Role of superoxide dismutase in cancer: a review. Cancer Res. 1979;39(4):1141-1149.

104. Oberley LW, Oberley TD, Buettner GR. Cell division in normal and transformed cells: the possible role of superoxide and hydrogen peroxide. Med Hypotheses. 1981;7(1):21-42.

105.Zou X, et al. Manganese superoxide dismutase (SOD2): is there a center in the universe of mitochondrial redox signaling? J Bioenerg Biomembr. 2017;49(4):325-333.

106. Wallace DC. A mitochondrial paradigm of metabolic and degenerative diseases, aging, and cancer: a dawn for evolutionary medicine. Annu Rev Genet. 2005;39:359-407.

107. Watanabe R, Nakamura H, Masutani H, Yodoi J Anti-oxidative, anti-cancer and anti-inflammatory actions by thioredoxin 1 and thioredoxin-binding protein-2. Pharmacol Ther. 2010;127(3):261-270.

108. Kim SJ, et al. High thioredoxin expression is associated with resistance to docetaxel in primary breast cancer. Clin Cancer Res. 2005;11(23):8425-8430.

109. Yang YJ, et al. Effective killing of cancer cells through ROS-mediated mechanisms by AMRI59 targeting peroxiredoxin I. Antioxid Redox Signal. 2016;24(8):453-469. 
110. Oberley LW, Oberley TD, Buettner GR. Cell differentiation, aging and cancer: the possible roles of superoxide and superoxide dismutases. Med Hypotheses. 1980;6(3):249-268.

111. Liu LZ, et al. Reactive oxygen species regulate epidermal growth factor-induced vascular endothelial growth factor and hypoxia-inducible factor-1 $\alpha$ expression through activation of AKT and P70S6K1 in human ovarian cancer cells. Free Radic Biol Med. 2006;41(10):1521-1533.

112. Gough DR, Cotter TG. Hydrogen peroxide: a Jekyll and Hyde signalling molecule. Cell Death Dis. 2011;2:e213.

113. Gao N, et al. Arsenite induces HIF-1alpha and VEGF through PI3K, Akt and reactive oxygen species in DU145 human prostate carcinoma cells. Mol Cell Biochem. 2004;255(1-2):33-45.

114. Pelicano $\mathrm{H}$, et al. Mitochondrial respiration defects in cancer cells cause activation of Akt survival pathway through a redox-mediated mechanism. J Cell Biol. 2006;175(6):913-923.

115. Lee SR, Yang KS, Kwon J, Lee C, Jeong W, Rhee SG. Reversible inactivation of the tumor suppressor PTEN by H2O2.J Biol Chem. 2002;277(23):20336-20342.

116. Salmeen A, et al. Redox regulation of protein tyrosine phosphatase $1 \mathrm{~B}$ involves a sulphenyl-amide intermediate. Nature. 2003;423(6941):769-773.

117. Quinn BJ, Kitagawa H, Memmott RM, Gills JJ, Dennis PA. Repositioning metformin for cancer prevention and treatment. Trends Endocrinol Metab. 2013;24(9):469-480.

118. Kasznicki J, Sliwinska A, Drzewoski J. Metformin in cancer prevention and therapy. Ann Transl Med. 2014;2(6):57.

119. Mohammed A, et al. Antidiabetic drug Metformin prevents progression of pancreatic cancer by targeting in part cancer stem cells and mTOR signaling. Transl Oncol. 2013;6(6):649-659.

120.Zakikhani M, Dowling R, Fantus IG, Sonenberg $\mathrm{N}$, Pollak M. Metformin is an AMP kinase-dependent growth inhibitor for breast cancer cells. Cancer Res. 2006;66(21):10269-10273.

121. Dowling RJ, Zakikhani M, Fantus IG, Pollak M, Sonenberg N. Metformin inhibits mammalian target of rapamycin-dependent translation initiation in breast cancer cells. Cancer Res. 2007;67(22):10804-10812.

122.Liou GY, Storz P. Reactive oxygen species in cancer. Free Radic Res. 2010;44(5):479-496.

123. Park MH, Jo M, Kim YR, Lee CK, Hong JT. Roles of peroxiredoxins in cancer, neurodegenerative diseases and inflammatory diseases. Pharmacol Ther. 2016;163:1-23.

124. Nicolussi A, D'Inzeo S, Capalbo C, Giannini G, Coppa A. The role of peroxiredoxins in cancer. Mol Clin Oncol. 2017;6(2):139-153.

125. Winterbourn CC. The biological chemistry of hydrogen peroxide. Meth Enzymol. 2013;528:3-25. 126. Woo HA, Yim SH, Shin DH, Kang D, Yu DY, Rhee SG. Inactivation of peroxiredoxin I by phosphorylation allows localized $\mathrm{H}(2) \mathrm{O}(2)$ accumulation for cell signaling. Cell. 2010;140(4):517-528.

127. Kil IS, et al. Feedback control of adrenal steroidogenesis via $\mathrm{H} 2 \mathrm{O} 2$-dependent, reversible inactivation of peroxiredoxin III in mitochondria. Mol Cell. 2012;46(5):584-594.

128. Hanahan D, Weinberg RA. Hallmarks of cancer: the next generation. Cell. 2011;144(5):646-674.

129. Hanahan D, Weinberg RA. The hallmarks of cancer. Cell. 2000;100(1):57-70.

130.Parrella P, et al. Detection of mitochondrial DNA mutations in primary breast cancer and fine-needle aspirates. Cancer Res. 2001;61(20):7623-7626

131. Polyak K, et al. Somatic mutations of the mitochondrial genome in human colorectal tumours. Nat Genet. 1998;20(3):291-293.

132. Habano W, Nakamura S, Sugai T. Microsatellite instability in the mitochondrial DNA of colorectal carcinomas: evidence for mismatch repair systems in mitochondrial genome. Oncogene. 1998;17(15):1931-1937.

133. Habano W, Sugai T, Yoshida T, Nakamura S. Mitochondrial gene mutation, but not large-scale deletion, is a feature of colorectal carcinomas with mitochondrial microsatellite instability. Int $J$ Cancer. 1999;83(5):625-629.

134. Máximo V, Soares P, Seruca R, Rocha AS, Castro P, Sobrinho-Simões M. Microsatellite instability, mitochondrial DNA large deletions, and mitochondrial DNA mutations in gastric carcinoma. Genes Chromosomes Cancer. 2001;32(2):136-143.

135. Jones JB, Song JJ, Hempen PM, Parmigiani G, Hruban RH, Kern SE. Detection of mitochondrial DNA mutations in pancreatic cancer offers a "mass"-ive advantage over detection of nuclear DNA mutations. Cancer Res. 2001;61(4):1299-1304.

136. Jerónimo $\mathrm{C}$, et al. Mitochondrial mutations in early stage prostate cancer and bodily fluids. Oncogene. 2001;20(37):5195-5198.

137. Yeh JJ, et al.Somatic mitochondrial DNA (mtDNA) mutations in papillary thyroid carcinomas and differential mtDNA sequence variants in cases with thyroid tumours. Oncogene. 2000;19(16):2060-2066.

138. Máximo V, Soares P, Lima J, Cameselle-Teijeiro J, Sobrinho-Simões M. Mitochondrial DNA somatic mutations (point mutations and large deletions) and mitochondrial DNA variants in human thyroid pathology: a study with emphasis on Hürthle cell tumors. Am J Pathol. 2002;160(5):1857-1865.

139. Carew JS, Huang P. Mitochondrial defects in cancer. Mol Cancer. 2002;1:9.

140. Chatterjee A, Mambo E, Sidransky D. Mitochondrial DNA mutations in human cancer. Oncogene. 2006;25(34):4663-4674.
141. Tan DJ, Bai RK, Wong LJ. Comprehensive scanning of somatic mitochondrial DNA mutations in breast cancer. Cancer Res. 2002;62(4):972-976.

142.Ivanova R, et al. Mitochondrial DNA sequence variation in human leukemic cells. Int J Cancer. 1998;76(4):495-498.

143. Gattermann N, et al. Heteroplasmic point mutations of mitochondrial DNA affecting subunit I of cytochrome c oxidase in two patients with acquired idiopathic sideroblastic anemia. Blood. 1997;90(12):4961-4972.

144. Reddy PL, et al. Increased incidence of mitochondrial cytochrome c-oxidase gene mutations in patients with myelodysplastic syndromes. $\mathrm{Br} \mathrm{J}$ Haematol. 2002;116(3):564-575.

145. Singh KK, Desouki MM, Franklin RB, Costello LC. Mitochondrial aconitase and citrate metabolism in malignant and nonmalignant human prostate tissues. Mol Cancer. 2006;5:14.

146.Ternette N, et al. Inhibition of mitochondrial aconitase by succination in fumarate hydratase deficiency. Cell Rep. 2013;3(3):689-700.

147. Wang P, et al. Decreased expression of the mitochondrial metabolic enzyme aconitase (ACO2) is associated with poor prognosis in gastric cancer. Med Oncol. 2013;30(2):552.

148. Tomlinson IP, et al. Germline mutations in FH predispose to dominantly inherited uterine fibroids, skin leiomyomata and papillary renal cell cancer. Nat Genet. 2002;30(4):406-410.

149. Fieuw $A$, et al. Identification of a novel recurrent 1q42.2-1qter deletion in high risk MYCN single copy $11 \mathrm{q}$ deleted neuroblastomas. Int J Cancer. 2012;130(11):2599-2606.

150. Sudarshan S, et al. Reduced expression of fumarate hydratase in clear cell renal cancer mediates HIF- $2 \alpha$ accumulation and promotes migration and invasion. PLoS One. 2011;6(6):e21037.

151. Lin CC, et al. Loss of the respiratory enzyme citrate synthase directly links the Warburg effect to tumor malignancy. Sci Rep. 2012;2:785.

152. Amary MF, et al. IDH1 and IDH2 mutations are frequent events in central chondrosarcoma and central and periosteal chondromas but not in other mesenchymal tumours. J Pathol. 2011;224(3):334-343.

153. Mitrunen K, et al. Association between manganese superoxide dismutase (MnSOD) gene polymorphism and breast cancer risk. Carcinogenesis. 2001;22(5):827-829.

154. Kamatani T, Yamamoto T, Yoneda K, Osaki T. Polymorphic mutations of the Mn-SOD gene in intact human lymphocytes and oral squamous cell carcinoma cell lines. Biochem Cell Biol. 2003;81(1):43-50.

155. Mikhak B, et al. Manganese superoxide dismutase (MnSOD) gene polymorphism, interactions with carotenoid levels and prostate cancer risk. Carcinogenesis. 2008;29(12):2335-2340. 